\title{
GMR
}

\section{Expression profiles of the apoptosis signaling pathway mediated by death receptor and endoplasmic reticulum in rat liver regeneration}

\author{
X.K. Xing ${ }^{1}$, M.H. $\mathrm{Li}^{2}$, X.S. Zhu ${ }^{1}$ and C.S. Xu \\ ${ }^{1}$ Department of Life Science and Technology, Xinxiang Medical University, \\ Xinxiang, China \\ ${ }^{2}$ National Glycoengineering Research Center, Shandong University, \\ Jinan, China \\ ${ }^{3}$ College of Life Science, Henan Normal University, Xinxiang, China \\ Corresponding author: C.S. Xu \\ E-mail: biyingxiao@163.com \\ Genet. Mol. Res. 15 (2): gmr. 15028288 \\ Received December 16, 2015 \\ Accepted February 11, 2016 \\ Published April 27, 2016 \\ DOI http://dx.doi.org/10.4238/gmr.15028288
}

\begin{abstract}
The death receptor and endoplasmic reticulum (ER) are closely related to cell apoptosis, and it is worth studying whether the apoptosis pathways mediated by them are involved in liver regeneration. To understand the mechanism underlying death receptor- and ERmediated apoptosis during rat liver regeneration, we used the Rat Genome 2302.0 Array to determine the changes in gene expression. We then searched the gene ontology (GO) and NCBI databases for genes associated with cell apoptosis mediated by the death receptor and ER. QIAGEN and KEGG databases were used for the related signaling pathways. We used the expression profile function to calculate the activity levels of the known apoptosis signaling pathways. The results of our study showed that the initial gene expression numbers in initiation, G0/G1 transition, cell proliferation, and redifferentiation and structural reconstruction phases were $32,25,44$, and 29 , respectively. This demonstrates that liver regeneration-related genes primarily start
\end{abstract}


their expression in the initiation phase and work differently in each phase. By calculation and analysis using the gene synergy formula, it was suggested that the apoptosis signaling pathways [FAS, death receptor 3 (DR3), tumor necrosis factor receptor 1 (TNFR1), and ER] induced cell apoptosis in whole liver regeneration and anti-apoptosis pathways (DR3 and TNFR2) restrained apoptosis in the early phase of liver regeneration. In summary, these apoptosis pathways coordinated and regulated quality and quantity of the regenerating liver cells.

Key words: Partial hepatectomy; Liver regeneration; Death receptor; Endoplasmic reticulum; Cell apoptosis

\section{INTRODUCTION}

Liver regeneration is an important process that allows the organ to recover from various pathological conditions, as well as from surgery or transplantation. Hepatocytes are parenchymal cells that are major contributors to liver regeneration. Under physiological conditions, less than $0.01 \%$ of hepatocytes in adult rat livers undergo mitosis. However, when the liver is injured by toxins, medication, and/or partial hepatectomy $(\mathrm{PH})$, the remaining hepatocytes can rapidly enter the cell cycle, together with other types of liver cells, to compensate for the lost tissue and restore liver function in a process referred to as liver regeneration. The liver regeneration process is usually divided into four stages: initiation (0.5$4 \mathrm{~h}$ after $\mathrm{PH}$ ), G0/G1 transition (4-6 h after $\mathrm{PH}$ ), cell proliferation (6-66 h after $\mathrm{PH}$ ), and redifferentiation and structural reconstruction (66-144 h after PH) (Xu et al., 2005). Numerous cellular events are involved in liver regeneration, including cell activation, de-differentiation, proliferation, re-differentiation, and remodeling of tissue structures.

Apoptosis, also known as programmed cell death (Green and Kroemer, 2004), is an initiative cell death process, which consumes energy and can be induced by a variety of factors. Cell apoptosis signals can come from outside or within the cell. Among these signals, the death receptor-mediated apoptosis pathway is the main pathway of cell apoptosis induced by external signals. The ligands include lipoteichoic acid, FAS ligand (FASL), Apo 3 ligand (APO3L), APO2L, tumor necrosis factor (TNF), TNF receptor 1 (TNFR1) (Neznanov et al., 2005), TNFR2 (Ventura et al., 2011), FAS (Hosono-Nishiyama et al., 2006), death receptor 3 (DR3) (Nishito et al., 2006), DR4, and DR5 (Tomasetti et al., 2006). These receptors are raised by the intracellular adaptor protein to raise the cysteine aspartate-specific protease precursor molecules, which are activated by the activation of the apoptotic cascade. The endoplasmic reticulum (ER) cell apoptosis pathway, a recently discovered endogenous pathway (Galluzzi et al., 2014), activates Caspase 12 (CASP12) through altered calcium ion concentration in the ER or non-folding/accumulation of proteins, resulting in CASP3 activation and consequent apoptosis (Liu and Baliga, 2005).

Apoptosis pathways mediated by the death receptor and ER contain 128 and 48 genes, respectively, and many interactions between genes and proteins. To understand the mechanism underlying death receptor- and ER-mediated apoptosis during rat liver regeneration at the gene transcription level, we used the Rat Genome 2302.0 Array, which contains 113 and 47 genes related to the death receptor and ER apoptosis pathways, respectively, to determine 
the expression changes of genes at $0.5,1,2,4,6,8,12,16,24,30,36,42,54,66,96$, and $144 \mathrm{~h}$ after PH (Calvano et al., 2005). We identified 40 and 15 death-receptor and ER genes, respectively, related to liver regeneration. We also employed the gene synergy formula (Et) (Xu et al., 2012) to analyze the interactions between the genes identified above in an effort to determine the role of death receptor and ER apoptosis pathway-related genes in rat liver regeneration (Durmuş et al., 2015; Fair and Rivas, 2015).

\section{MATERIAL AND METHODS}

\section{Rat PH model}

Adult (6 weeks old) male Sprague-Dawley rats weighing $230 \pm 20 \mathrm{~g}$ were obtained from Henan Normal University's animal center. The rats were housed at a temperature of $21^{\circ}$ $\pm 2^{\circ} \mathrm{C}$ and relative humidity of $60 \pm 10 \%$. They received $12 \mathrm{~h}$ of light per day (8:00-20:00) and free access to food and water. A total of 114 rats were randomly divided into 19 groups with six rats per group: nine groups underwent a two-thirds hepatectomy (PH groups), nine groups underwent a "sham" operation (SO groups), and one group had no operation (control group). Rats in the PH groups had the left and median lateral liver lobes removed. The rats in the SO groups underwent the same operation without removal of the liver lobes. Rats were sacrificed $0,2,6,12,24,30,36,72,120$, and $168 \mathrm{~h}$ after the operations. All study procedures complied with Chinese animal protection laws.

\section{Rat genome 2302.0 microarray detection and analysis}

Total RNA was extracted and purified following the same protocol as a previously published study (Xu et al., 2012). Briefly, biotin-labeled cRNA was prepared using the GeneChip IVT kit (Affymetrix Inc., USA) according to the manufacturer instructions. Hybridization was conducted automatically using a GeneChip Fluidics Station 450 (Affymetrix Inc.). The results were scanned and converted into signal values using a GeneChip scanner 3000 (Affymetrix Inc.), then signal values were normalized according to the manufacturer instructions.

The $\mathrm{P}$ values were determined using the Affymetrix GCOS 2.0 software. If the $\mathrm{P}$ value of a gene was $<0.05$, the gene was defined as present $(\mathrm{P}) ; \mathrm{P}<0.065$ was defined as marginal $(\mathrm{M})$, and $\mathrm{P}>0.065$ was defined as absent $(\mathrm{A})$. Any gene was considered significantly changed if the ratio of its $P$ value relative to that of the control was $\geq 3$ or $\leq 0.33$.

The significance of gene expression differences between $\mathrm{PH}$ and $\mathrm{SO}$ groups was analyzed with the F-test. Genes found to change significantly for at least one time point during liver regeneration $(\mathrm{P}<0.05)$ were defined as genes associated with liver regeneration. To minimize errors due to experimental operation and microarray, three repetitions were performed at each time point and the average value of the three independent assays was used for statistical analyses.

\section{Et analysis}

Xu et al. (2012) established the mathematical model $\mathrm{E}(\mathrm{t})$ to describe how physiological activities are governed by gene synergy according to the expression levels of genes detected 
by the Rat Genome 2302.0 Microarray. Based on the methods of multivariate statistics and time series analysis and the fact that physical activity is regulated by the synergy of one lot of genes to another, the following spectrum function was employed:

$$
E_{t} \frac{\sum_{i=l}^{n} \sum_{k=l}^{n}\left[\left(\mathrm{X}_{\mathrm{i}}^{(t)}+X_{k}^{(t)}\right)^{*} \mathrm{r}_{\mathrm{ik}}\right]}{n(n+1)}
$$

where the gene correlation coefficient $\left(\mathrm{r}_{\mathrm{ik}}\right)$ is defined by the Pearson correlation coefficient:

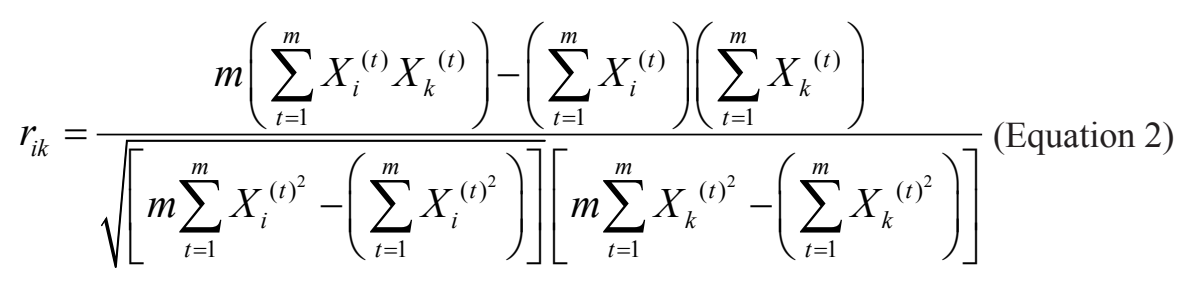

where $n$ is the number of all genes participating in a physiological activity at time point $t$. The spectral function $\mathrm{E}(\mathrm{t})$ describes the effectiveness of the gene synergy dominating a physiological activity at one point. By comparisons against a control, the strength of the physiological activities at a certain time can be predicted. At time $t$, assuming that the reference value is $\mathrm{E}(0)$, the corresponding physical activity is stronger than the control when $\mathrm{E}(\mathrm{t})-\mathrm{E}(0)$ $\geq \mathrm{E}(0)$, weaker when $\mathrm{E}(\mathrm{t})-\mathrm{E}(0)<0$, and similar when $\mathrm{E}(0)<\mathrm{E}(\mathrm{t})<2 \mathrm{E}(0)$.

\section{RESULTS}

\section{Gene profiles related to death receptor- and ER-mediated apoptosis signaling pathways}

According to data from NCBI and gene ontology (GO) databases and biological pathway maps in QIAGEN and KEGG, there are 128 and 48 genes involved in the death receptor- and ER-mediated apoptosis signaling pathways, respectively. Of these, 113 death receptor and 47 ER genes are present on the Rat Genome 230 2.0 Microarray. Our array analysis showed that 40 death receptor and 15 ER genes were significantly changed in regenerating hepatocytes, which were identified as liver regeneration-related genes by comparing the differential expression in PH and SO groups. Of these genes, 25 were upregulated; 20, downregulated; and 4, upregulated at certain time points and downregulated at other time points (we called these "up/downregulated") during rat liver regeneration (Table 1).

At various time points, genes were upregulated and downregulated a total of 173 and 95 times, respectively. At the initiation phase (0.5-4 h after PH), 14 genes were upregulated; 17, downregulated; and 1, up/downregulated. At G0/G1 transition (4-6 h after PH), 14 genes were upregulated; and 11, downregulated. At cell proliferation (6-66 h after PH), 24 genes 
were upregulated; 17, downregulated; and 2, up/downregulated. At the redifferentiation and structural reconstruction phase (66-144 h after PH), 18 genes were upregulated; and 11, downregulated (Figure 1).

\begin{tabular}{|c|c|c|c|c|c|c|c|c|c|c|c|c|c|c|c|c|c|c|}
\hline \multirow[t]{2}{*}{ Abbr } & \multirow[t]{2}{*}{ Pathways } & \multicolumn{17}{|c|}{ Recovery time (h) after partial hepatectomy (PH) } \\
\hline & & 0 & 0.5 & 1 & 2 & 4 & 6 & 8 & 12 & 16 & 24 & 30 & 36 & 42 & 54 & 66 & 96 & 144 \\
\hline bcl2al & 1 & 1.00 & 1.15 & 2.00 & 2.00 & 0.93 & 1.32 & 1.23 & 0.93 & 0.93 & 0.93 & 1.41 & 1.00 & 0.81 & 0.81 & 0.81 & 1.00 & 1.15 \\
\hline casp1 & 1 & 1.00 & 0.93 & 1.00 & 1.00 & 0.81 & 0.93 & 1.00 & 0.93 & 4.52 & 1.00 & 0.76 & 0.93 & 1.00 & 2.30 & 1.62 & 0.87 & 0.87 \\
\hline casp8ap2 & 1 & 1.00 & 2.19 & 3.76 & 8.52 & 4.16 & 5.37 & 5.46 & 2.33 & 3.45 & 3.45 & 2.89 & 2.99 & 2.17 & 1.65 & 3.63 & 4.84 & 7.47 \\
\hline dap3 & 1 & 1.00 & 4.92 & 1.52 & 2.14 & 5.28 & 3.73 & 5.28 & 4.59 & 3.25 & 3.73 & 3.25 & 3.73 & 4.59 & 1.00 & 2.82 & 3.74 & 3.48 \\
\hline egr2 & 1 & 1.00 & 1.21 & 1.33 & 3.64 & 9.28 & 5.16 & 6.51 & 5.16 & 3.28 & 4.24 & 2.24 & 3.74 & 3.04 & 3.14 & 4.80 & 3.73 & 6.01 \\
\hline gadd $45 b$ & 1 & 1.00 & 2.14 & 2.46 & 1.62 & 2.64 & 2.00 & 4.00 & 1.41 & 1.87 & 2.30 & 1.52 & 1.74 & 3.25 & 1.41 & 2.64 & 5.99 & 3.48 \\
\hline ifnal & 1 & 1.00 & 1.00 & 0.35 & 1.07 & 0.31 & 1.32 & 0.81 & 0.38 & 0.62 & 0.81 & 1.00 & 1.41 & 0.81 & 1.07 & 0.87 & 1.07 & 0.87 \\
\hline il10 & 1 & 1.00 & 1.32 & 1.23 & 0.87 & 1.07 & 0.71 & 0.57 & 0.41 & 0.54 & 0.66 & 0.66 & 0.66 & 0.71 & 0.76 & 0.87 & 1.23 & 0.81 \\
\hline lck & 1 & 1.00 & 1.15 & 0.15 & 1.07 & 1.23 & 1.62 & 0.20 & 1.87 & 0.41 & 0.81 & 0.47 & 0.81 & 1.07 & 1.23 & 1.32 & 0.87 & 2.14 \\
\hline map3k5 & 1 & 1.00 & 1.23 & 0.47 & 1.07 & 0.66 & 1.52 & 1.00 & 1.00 & 1.52 & 1.00 & 0.81 & 1.52 & 1.07 & 0.93 & 0.93 & 1.87 & 0.62 \\
\hline ncf1 & 1 & 1.00 & 0.93 & 1.07 & 1.74 & 1.41 & 2.14 & 5.66 & 1.41 & 3.73 & 1.52 & 0.87 & 4.92 & 1.07 & 1.00 & 1.62 & 1.32 & 8.00 \\
\hline smpd1 & 1 & 1.00 & 1.00 & 0.41 & 0.66 & 0.27 & 0.71 & 1.00 & 0.62 & 0.81 & 0.76 & 0.71 & 0.47 & 1.07 & 0.54 & 0.76 & 2.00 & 0.81 \\
\hline casp9 & $1,2,3$ & 1.00 & 1.00 & 1.41 & 0.33 & 0.63 & 0.81 & 1.23 & 0.81 & 0.64 & 0.67 & 0.49 & 0.22 & 0.57 & 0.38 & 0.59 & 0.31 & 0.73 \\
\hline cad & $1,2,3,4$ & 1.00 & 2.50 & 1.29 & 1.39 & 1.84 & 2.02 & 1.54 & 1.99 & 1.81 & 1.74 & 2.18 & 2.48 & 2.32 & 2.22 & 2.09 & 0.46 & 1.88 \\
\hline casp6 & $1,2,3,4$ & 1.00 & 1.32 & 0.81 & 0.76 & 0.19 & 0.44 & 0.57 & 1.32 & 0.38 & 0.81 & 0.76 & 0.76 & 0.66 & 0.50 & 0.23 & 2.80 & 1.71 \\
\hline casp7 & $1,2,3,4$ & 1.00 & 1.02 & 1.32 & 0.96 & 1.22 & 1.32 & 1.86 & 2.24 & 1.66 & 1.47 & 0.82 & 1.44 & 1.20 & 1.00 & 1.37 & 0.54 & 1.85 \\
\hline casp3 & $1,2,3,4,6$ & 1.00 & 0.82 & 0.88 & 0.62 & 0.83 & 0.58 & 0.32 & 0.89 & 0.75 & 0.97 & 0.63 & 0.73 & 0.92 & 0.85 & 0.82 & 1.37 & 0.97 \\
\hline casp8 & $1,2,3,4,6$ & 1.00 & 0.57 & 1.74 & 0.93 & 0.54 & 0.44 & 0.15 & 1.15 & 1.52 & 1.52 & 1.15 & 0.54 & 1.32 & 1.41 & 1.62 & 0.74 & 1.23 \\
\hline tradd & $1,2,4$ & 1.00 & 2.14 & 1.00 & 0.93 & 0.87 & 2.64 & 2.83 & 1.52 & 1.15 & 0.93 & 0.87 & 0.93 & 0.93 & 0.87 & 3.73 & 1.15 & 1.32 \\
\hline $\operatorname{tp} 53$ & $1,3,4$ & 1.00 & 0.89 & 0.93 & 1.09 & 0.95 & 0.91 & 3.55 & 1.24 & 0.91 & 1.05 & 0.76 & 0.98 & 0.83 & 0.85 & 4.44 & 2.64 & 3.68 \\
\hline nfkb1 & $1,3,5,6$ & 1.00 & 0.47 & 1.07 & 0.44 & 0.66 & 0.23 & 0.41 & 0.71 & 0.50 & 0.66 & 0.38 & 0.44 & 0.50 & 0.71 & 0.47 & 2.01 & 0.38 \\
\hline casp2 & 1,4 & 1.00 & 0.91 & 0.39 & 1.09 & 0.73 & 0.56 & 1.01 & 0.88 & 0.68 & 1.02 & 0.72 & 0.74 & 1.29 & 0.42 & 1.14 & 0.35 & 0.50 \\
\hline lmna & 1,4 & 1.00 & 1.02 & 0.74 & 1.97 & 1.26 & 1.72 & 4.19 & 1.59 & 0.91 & 0.77 & 0.68 & 3.19 & 2.43 & 0.74 & 1.02 & 0.95 & 1.31 \\
\hline pb1 & 1,4 & 1.00 & 0.93 & 0.87 & 0.76 & 1.00 & 0.76 & 0.81 & 1.00 & 1.00 & 4.00 & 0.81 & 0.93 & 0.93 & 0.66 & 1.23 & 0.31 & 1.07 \\
\hline bak1 & 1,6 & 1.00 & 3.48 & 8.00 & 3.25 & 2.00 & 6.06 & 5.28 & 1.15 & 4.29 & 3.03 & 3.48 & 4.29 & 1.87 & 3.03 & 6.96 & 1.15 & 4.92 \\
\hline birc5 & 1,6 & 1.00 & 0.23 & 0.35 & 0.33 & 0.71 & 0.22 & 1.00 & 0.87 & 0.33 & 0.93 & 0.57 & 0.33 & 1.15 & 0.81 & 0.29 & 4.00 & 0.31 \\
\hline $\operatorname{tnfsf12}$ & 2 & 1.00 & 0.31 & 1.00 & 1.15 & 0.76 & 0.76 & 1.41 & 1.52 & 1.07 & 1.00 & 1.32 & 0.25 & 1.41 & 1.15 & 1.15 & 0.22 & 0.41 \\
\hline cyct & 2,3 & 1.00 & 0.84 & 1.07 & 0.95 & 1.49 & 1.16 & 3.46 & 0.76 & 1.42 & 1.21 & 0.79 & 1.20 & 0.92 & 0.79 & 1.83 & 0.33 & 1.57 \\
\hline bag4 & 2,4 & 1.00 & 0.93 & 0.66 & 0.81 & 0.66 & 1.07 & 1.07 & 1.23 & 0.93 & 0.87 & 1.23 & 0.57 & 0.81 & 1.00 & 0.41 & 1.18 & 0.38 \\
\hline ccr5 & 3 & 1.00 & 0.71 & 1.07 & 0.71 & 0.33 & 0.54 & 1.00 & 0.71 & 1.00 & 0.66 & 0.87 & 1.00 & 1.00 & 0.57 & 1.32 & 0.87 & 1.41 \\
\hline map2k1 & 3 & 1.00 & 4.76 & 4.44 & 2.47 & 3.26 & 2.44 & 3.22 & 2.13 & 1.61 & 0.95 & 1.07 & 1.77 & 7.60 & 7.17 & 0.86 & 0.66 & 2.40 \\
\hline mapk8 & 3,4 & 1.00 & 0.54 & 0.76 & 1.87 & 0.62 & 0.93 & 0.93 & 1.62 & 2.30 & 0.93 & 1.52 & 0.87 & 0.41 & 0.87 & 0.81 & 0.93 & 1.07 \\
\hline mapk1 & 3,5 & 1.00 & 1.96 & 1.71 & 1.71 & 1.55 & 1.62 & 2.43 & 1.22 & 2.45 & 1.81 & 1.03 & 2.25 & 2.26 & 1.19 & 2.17 & 1.23 & 1.85 \\
\hline arhgdib & 4 & 1.00 & 3.73 & 6.50 & 8.57 & 2.83 & 4.92 & 8.00 & 3.03 & 9.85 & 6.50 & 1.23 & 8.57 & 5.66 & 3.73 & 13.00 & 13.00 & 27.86 \\
\hline ripk1 & 4 & 1.00 & 1.09 & 0.43 & 0.92 & 0.83 & 1.21 & 1.54 & 0.88 & 1.31 & 1.07 & 0.70 & 0.79 & 0.58 & 0.88 & 1.38 & 0.80 & 1.38 \\
\hline rela & 4,6 & 1.00 & 0.54 & 0.50 & 1.15 & 0.71 & 0.93 & 1.74 & 1.23 & 1.41 & 1.23 & 0.57 & 0.87 & 0.81 & 0.54 & 1.62 & 1.07 & 1.41 \\
\hline chuk & 5 & 1.00 & 0.25 & 0.31 & 0.12 & 0.41 & 0.47 & 0.57 & 0.38 & 1.32 & 0.31 & 0.31 & 0.81 & 1.23 & 1.32 & 0.22 & 0.47 & 0.41 \\
\hline ikbkb & 5 & 1.00 & 0.71 & 0.50 & 0.66 & 0.41 & 0.41 & 1.23 & 0.54 & 0.33 & 0.71 & 0.25 & 1.00 & 0.38 & 0.57 & 0.87 & 1.00 & 1.41 \\
\hline lta & 5 & 1.00 & 0.66 & 0.93 & 1.00 & 0.81 & 0.62 & 2.00 & 0.62 & 0.87 & 0.81 & 1.41 & 0.81 & 1.74 & 0.62 & 2.46 & 2.00 & 2.30 \\
\hline nfkbia & 5 & 1.00 & 4.59 & 1.41 & 2.64 & 1.23 & 1.74 & 1.23 & 2.64 & 1.74 & 1.41 & 6.06 & 1.07 & 1.74 & 1.00 & 1.23 & 0.87 & 1.41 \\
\hline bcr & 6 & 1.00 & 1.24 & 1.12 & 0.89 & 0.96 & 1.03 & 1.67 & 2.46 & 0.95 & 0.61 & 1.01 & 0.76 & 0.64 & 0.53 & 1.43 & 1.86 & 1.13 \\
\hline bmf & 6 & 1.00 & 1.15 & 1.74 & 1.74 & 2.30 & 1.62 & 1.62 & 0.81 & 1.41 & 1.32 & 0.93 & 3.25 & 1.07 & 1.32 & 2.64 & 1.41 & 2.46 \\
\hline capn1 & 6 & 1.00 & 0.41 & 0.25 & 0.62 & 0.81 & 0.33 & 0.87 & 0.44 & 0.23 & 0.27 & 0.50 & 0.25 & 0.16 & 0.25 & 0.31 & 0.33 & 0.71 \\
\hline casp12 & 6 & 1.00 & 0.33 & 0.54 & 0.54 & 0.50 & 0.54 & 0.54 & 0.38 & 1.32 & 2.14 & 0.35 & 0.29 & 0.93 & 0.54 & 1.32 & 1.87 & 1.74 \\
\hline erbb2 & 6 & 1.00 & 1.15 & 1.52 & 1.87 & 1.23 & 1.52 & 1.62 & 0.50 & 1.41 & 0.93 & 1.00 & 1.00 & 1.23 & 1.00 & 0.33 & 1.15 & 0.57 \\
\hline frap1 & 6 & 1.00 & 0.31 & 0.76 & 3.25 & 1.52 & 2.00 & 2.46 & 1.00 & 1.52 & 3.25 & 1.41 & 1.32 & 1.23 & 1.52 & 2.46 & 2.14 & 2.30 \\
\hline gja1 & 6 & 1.00 & 1.35 & 3.79 & 1.52 & 2.44 & 2.94 & 2.80 & 1.71 & 1.84 & 1.76 & 0.72 & 1.83 & 0.94 & 1.75 & 3.05 & 1.96 & 4.50 \\
\hline $\mathrm{rtn} 3$ & 6 & 1.00 & 3.65 & 4.11 & 4.22 & 3.02 & 3.68 & 4.70 & 3.67 & 4.19 & 4.15 & 1.96 & 3.44 & 2.15 & 4.48 & 4.62 & 2.83 & 5.04 \\
\hline tlr2 & 6 & 1.00 & 1.07 & 0.76 & 0.66 & 0.81 & 1.07 & 0.87 & 1.74 & 1.74 & 2.00 & 2.30 & 1.52 & 1.74 & 1.52 & 1.32 & 1.15 & 1.15 \\
\hline
\end{tabular}

1, FAS signaling pathway; 2, DR3 signaling pathway; 3, DR4/5 signaling pathway; 4, TNFR1 signaling pathway; 5 , TNFR2 signaling pathway; 6 , endoplasmic reticulum signaling pathway; gray means upregulated, green means downregulated.

According to the array data, at each liver regeneration time point, the upregulation and downregulation numbers of initially and totally expressed genes are as follows: 10 and 7, 10 and 7 at $0.5 \mathrm{~h} ; 8$ and 2,8 and 11 at $1 \mathrm{~h} ; 3$ and 1,9 and 4 at $2 \mathrm{~h} ; 1$ and 2, 10 and 7 at $4 \mathrm{~h} ; 1$ and 
1,13 and 7 at $6 \mathrm{~h} ; 5$ and 1,17 and 3 at $8 \mathrm{~h} ; 2$ and 2,9 and 6 at $12 \mathrm{~h} ; 1$ and 0,9 and 6 at $16 \mathrm{~h} ; 3$ and 0,11 and 2 at $24 \mathrm{~h} ; 0$ and 0,7 and 7 at $30 \mathrm{~h} ; 0$ and 0,11 and 7 at $36 \mathrm{~h} ; 0$ and 1,10 and 4 at $42 \mathrm{~h} ; 1$ and 0,7 and 4 at $54 \mathrm{~h} ; 0$ and 1,15 and 7 at $66 \mathrm{~h} ; 0$ and 0,12 and 7 at $96 \mathrm{~h}$; and 0 and 0,15 and 6 at $144 \mathrm{~h}$ (Figure 2).

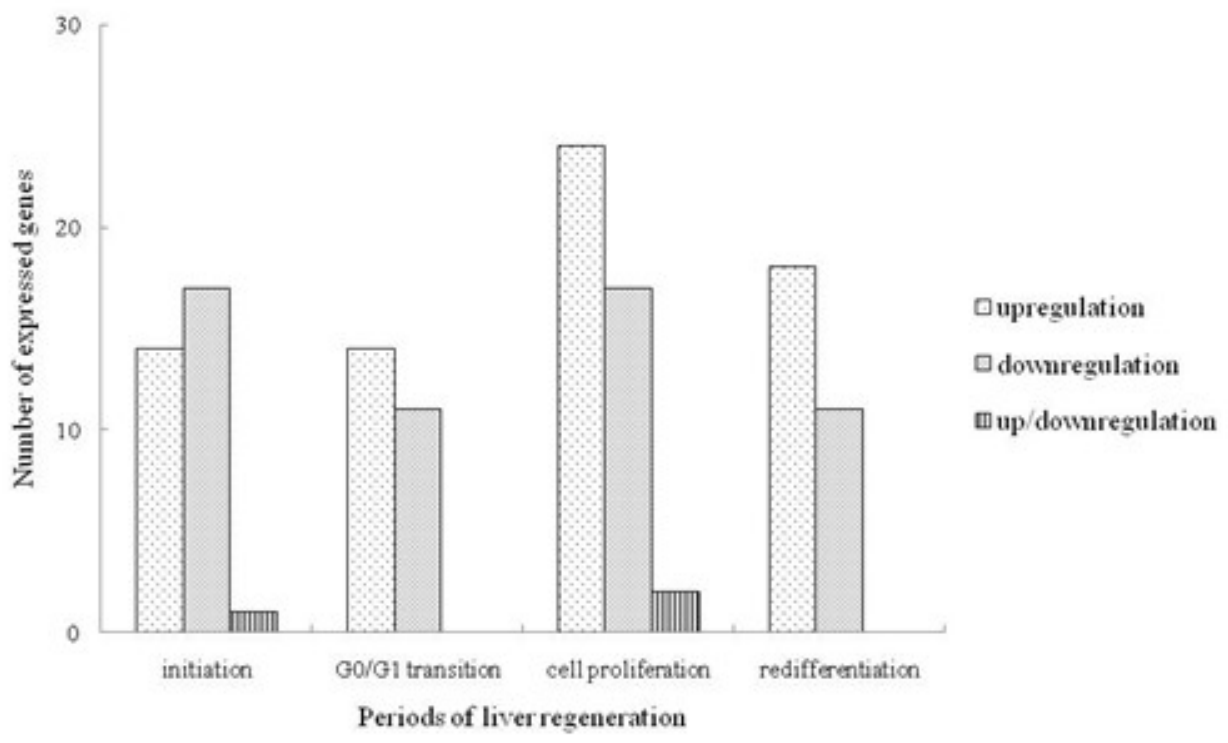

Figure 1. Gene expression at different periods of liver regeneration.

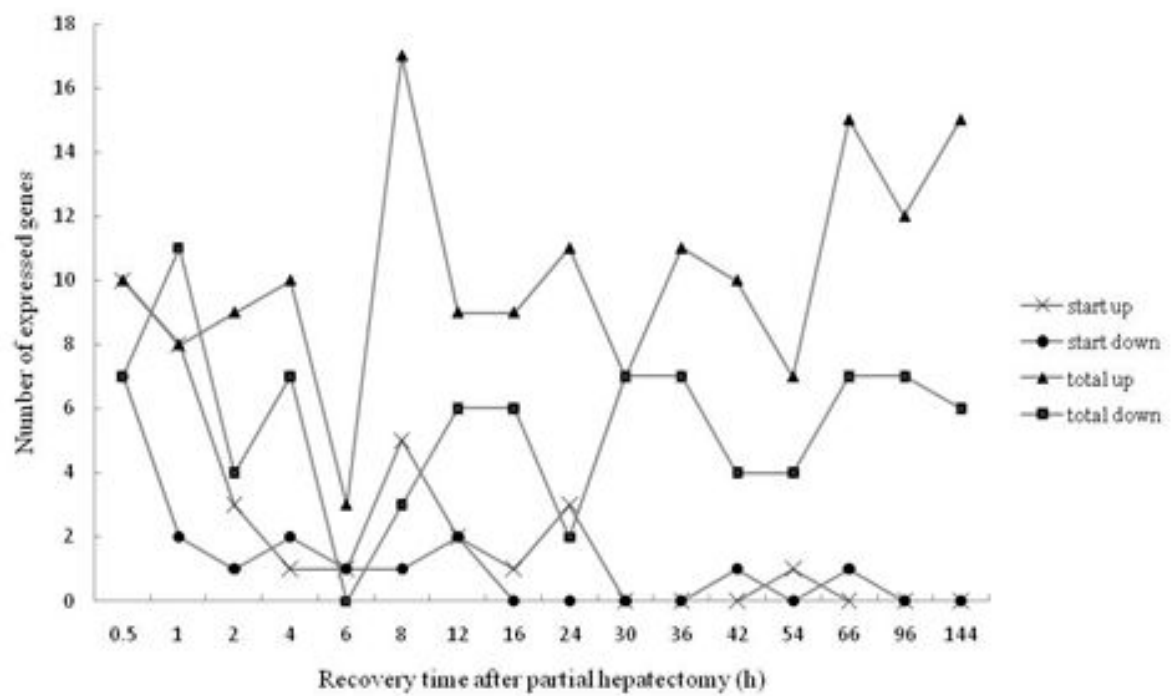

Figure 2. Starting expression and total expression of apoptosis-related genes in liver regeneration at each time point. 


\section{Similarity and temporal correlation between genes}

According to the similarity of liver regeneration-related gene expression, the 40 death receptor and 15 ER genes described above can be divided into 5 categories: all upregulated, dominant upregulated, all downregulated, dominant downregulated, and similar up- or downregulated, which involved 25, 1, 20, 2, and 1 gene(s), respectively. According to the time correlation of gene expression during liver regeneration, these genes can be divided into 9 groups: 0.5 h, 1 and 4 h, 2 and 6 h, 8 h, 12 and 30 h, 16 and 24 h, 36 h, 42 and 54 h, and 66-144 $\mathrm{h}$, where the number of upregulated and downregulated genes were 10 and 7, 11 and 14, 14 and 8,17 and 3,12 and 10,14 and 7,11 and 7,12 and 7, and 18 and 11, respectively (Figure 3).

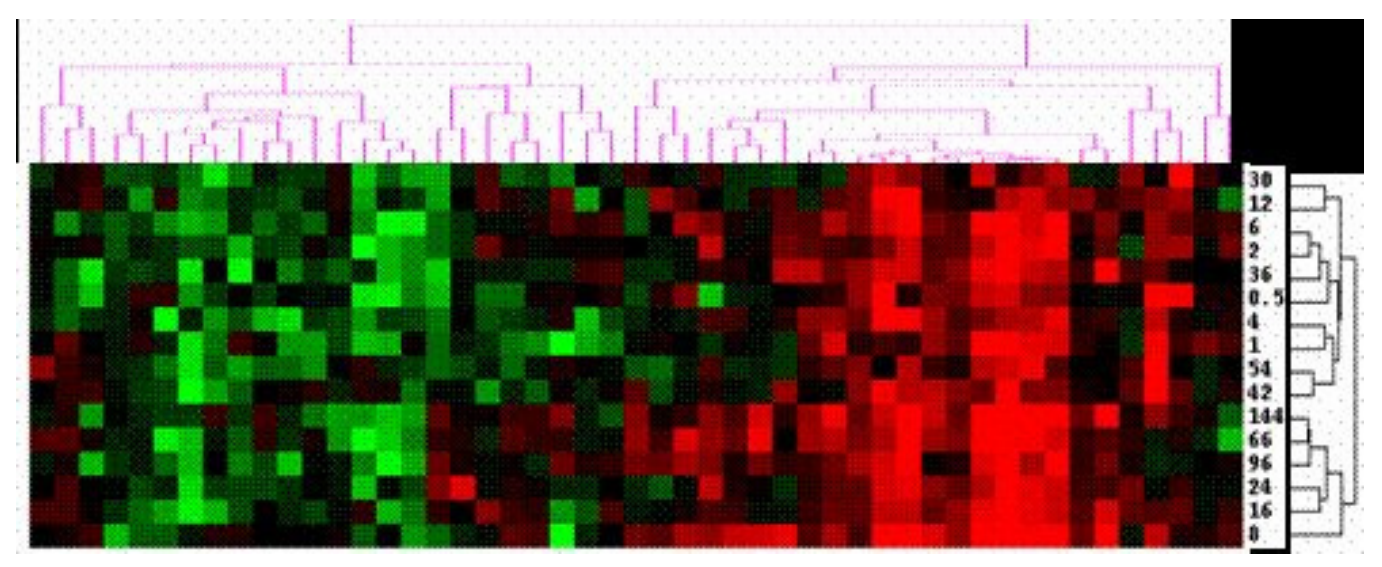

Figure 3. Similarity clustering and temporal correlation of gene expression related to death receptor- and endoplasmic reticulum-mediated apoptosis signaling pathways during liver regeneration. Red represents upregulated genes; green, downregulated genes; and black, no significant change in expression. Pink tree shows similarity clustering; and black tree, temporal correlation clustering.

\section{Correlation between genes}

To analyze the correlation between the genes related to death receptor- and ERmediated apoptotic signaling pathways and liver regeneration, the spectrum function $\mathrm{E}(\mathrm{t})$ was used to analyze the gene synergetic effects. The $\mathrm{E}(\mathrm{t})$ values of genes related to the FAS apoptosis pathway were significantly higher than those of the control at $144 \mathrm{~h}$ after PH (Figure 4A). The $\mathrm{E}(\mathrm{t})$ values of genes related to the DR3-mediated apoptosis pathway were significantly higher than those of the control at $66 \mathrm{~h}$ after PH (Figure 4B). The E(t) values of genes related to the DR3-mediated anti-apoptosis pathway were significantly higher than those of the control at $30 \mathrm{~h}$ after $\mathrm{PH}$ (Figure $4 \mathrm{C}$ ). The $\mathrm{E}(\mathrm{t})$ values of genes related to the DR4/5 apoptosis pathway were lower than those of the control at each time point after PH (Figure 4D). The E(t) values of genes related to the TNFR1 apoptosis pathway were significantly higher than those of the control at 2, 8, 16, 24, 36, and 66-144 h after PH (Figure 4E). The E(t) values of genes related to the TNFR1 anti-apoptosis pathway were lower than those of the control at each time point after PH (Figure 4F). The E(t) values of genes related to the TNFR2 anti-apoptosis pathway 
were significantly higher than those of the control at 0.5 and $30 \mathrm{~h}$ after $\mathrm{PH}$ (Figure $4 \mathrm{G}$ ). The $\mathrm{E}(\mathrm{t})$ values of genes related to the ER apoptosis pathway were significantly higher than those of the control at 8, 66, and $144 \mathrm{~h}$ after PH (Figure 4H).

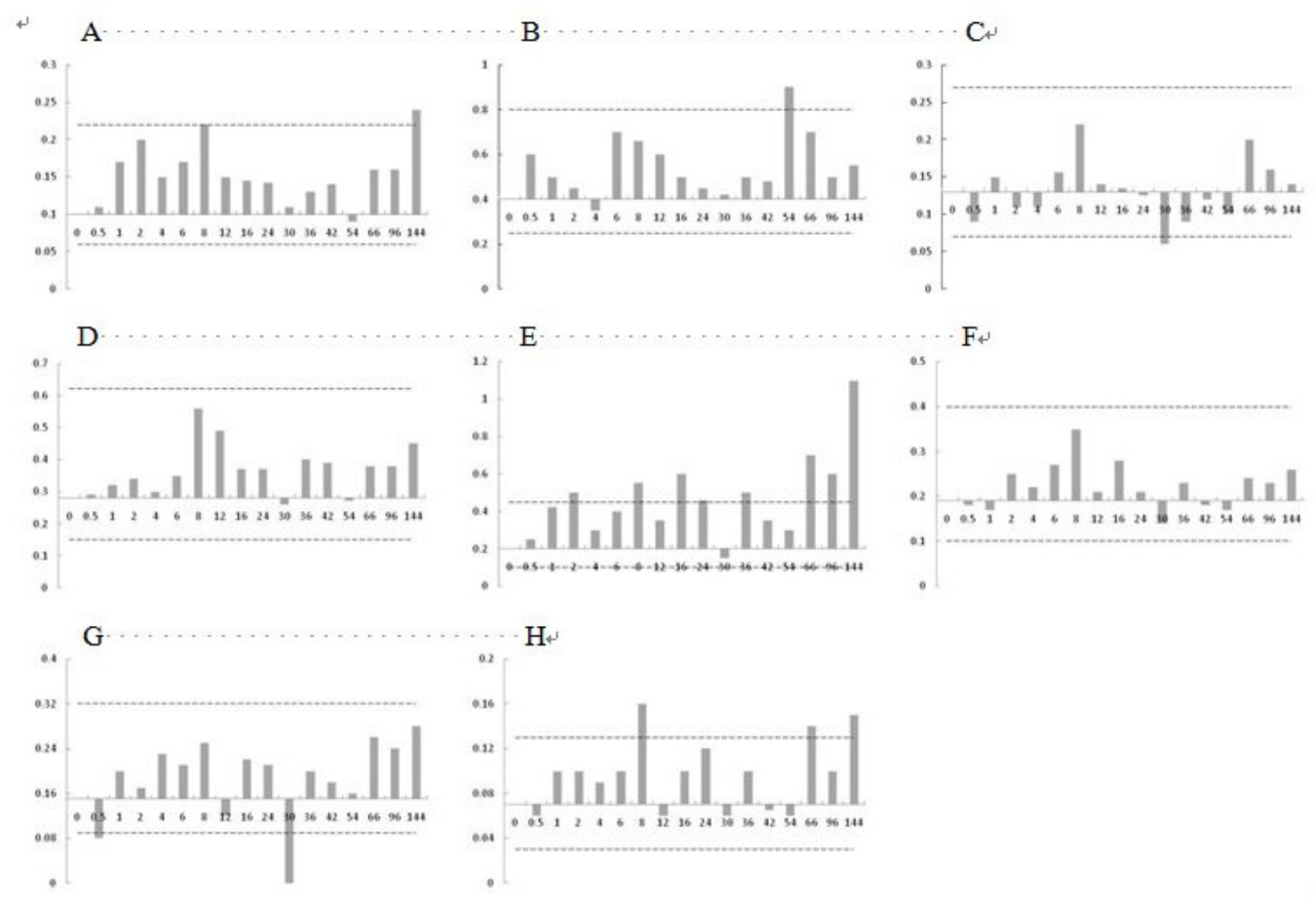

Figure 4. Role of apoptosis pathways in liver regeneration. A. FAS apoptosis pathway. B. DR3 apoptosis pathway. C. DR3 anti-apoptosis pathway. D. DR4/5 apoptosis pathway. E. TNFR1 apoptosis pathway. F. TNFR1 antiapoptosis pathway. G. TNFR2 anti-apoptosis pathway. H. Endoplasmic reticulum apoptosis pathway. X-axis is recovery time after partial hepatectomy $(\mathrm{h})$ and $\mathrm{y}$-axis is spectrum function $\mathrm{E}(\mathrm{t})$.

\section{DISCUSSION}

The primary focus of this study was to examine the role of expression changes in genes related to apoptosis signaling pathways mediated by FAS, DR3, DR4/5, TNFR1, and TNFR2 during rat liver regeneration. Among them, mitogen-activated protein kinase kinase kinase 5 (MAP3K5) can combine with thymoma viral proto-oncogene (AKT) and heat-shock protein 90 (HSP90) to form a complex that protects cells from stress-induced apoptosis (Zhang et al., 2005). TNFR superfamily receptor-interacting serine-threonine kinase 1 (RIPK1) can interact with TNFR superfamily member $1 / 6$ (TNFRSF1/6) to induce cell apoptosis (Kurenova et al., 2004). Both were upregulated $1 \mathrm{~h}$ after PH and might regulate cell apoptosis together.

Guanosine diphosphate dissociation inhibitor beta (ARHGDIB) is transferred to the nucleus after being cleaved into 23-kDa pieces by CASP3 (Kwon et al., 2002). ARHGDIB was upregulated during the entirety of liver regeneration and might play a key role in regulating cell apoptosis. Caspase 8 associated protein 2 (CASP8AP2) is involved in cell activation 
mediated by nuclear factor kappa B (NFkB) (Jun et al., 2005) and cell survival. CASP8AP2 was upregulated during the entirety of liver regeneration and might inhibit cell apoptosis.

B-cell leukemia/lymphoma 2 modifying factor (BMF) promoted injured cell apoptosis (Puthalakath et al., 2001). It was upregulated 4, 36, 66, and $144 \mathrm{~h}$ after $\mathrm{PH}$, indicating promotion of apoptosis in injured, defective, and excess cells. Carbamoyl phosphate synthetase II (CAD) can bind with histone $\mathrm{H} 1$ to induce DNA fragmentation (Korn et al., 2005). It was upregulated $0.5,6$, and 30-96 h after PH and may promote apoptosis. CASP7 is often activated first and then activates other hydrolytic enzymes to promote apoptosis (Borghetti et al., 2015). CASP7 was upregulated $12 \mathrm{~h}$ after PH and it may promote the apoptosis of defective cells. MAP2K1 can increase the expression of DR4 and DR5, and enhance the affinity of the TNFrelated apoptosis-inducing ligand (TRAIL) (Drosopoulos et al., 2005). TNFRSF member 1A-associated death domain (TRADD) together with TNFRSF member 6-associated death domain protein (FADD) and CASP8 promote cell apoptosis (Bender et al., 2005). TRADD was upregulated 0.5 and $6-8 \mathrm{~h}$ after $\mathrm{PH}$ and might promote injured cell apoptosis. TRADD was also upregulated 66-96 $\mathrm{h}$ after $\mathrm{PH}$ and might promote the apoptosis of excess cells. B-cell leukemia/lymphoma 2-associated athanogene 4 (BAG4) inhibits cell apoptosis (Antoku et al., 2001). BAG4 was downregulated 66 and $144 \mathrm{~h}$ after PH and might promote apoptosis of defective and excess cells. TNF ligand superfamily member 12 (TNFSF12) promotes cell survival by inducing BCL-XL/BCL-W expression through NFKB (Tran et al., 2005). TNFSF 12 was downregulated $0.5,36,96$, and $144 \mathrm{~h}$ after $\mathrm{PH}$, and might promote apoptosis of injured, defective, and excess cells.

Breakpoint cluster region (BCR) can inhibit the release of cytochrome $\mathrm{C}$ from mitochondria and activation of cysteine-specific protease (Deming et al., 2004). BCR was upregulated $16 \mathrm{~h}$ after PH and inhibited cell apoptosis. CASP12 can induce apoptosis during calcium depletion of the ER (Díaz-Horta et al., 2003). CASP12 was downregulated at 0.5, 4,12 , and 30-36 $\mathrm{h}$ after $\mathrm{PH}$ and inhibited apoptosis in the early and middle stages of liver regeneration.

Lamin A (LMNA) is associated with chromosome attachment and anchoring (Meaburn et al., 2005). LMNA was upregulated 8, 36, and $42 \mathrm{~h}$ after PH and might play a key role in maintaining the stability of chromosome structure in cell proliferation. CASP6 can induce the degradation of the nucleus protein fiber layer A (MacLachlan and El-Deiry, 2002). CASP6 was downregulated 4, 6, 16, and 54-66 h after $\mathrm{PH}$ and might be involved in maintaining the stability of chromosome structure. Conserved helix-loop-helix ubiquitous kinase (CHUK) promotes the pro-protein p100 to become p52, which is part of the NFKB complex (Qing and Xiao, 2005). CHUK was downregulated during the entirety of liver regeneration, indicating the weak role of NFkB in liver regeneration. Growth arrest and DNA-damage-inducible 45 beta (GADD45B) is involved in increasing the cell volume during rat liver regeneration. This is consistent with the reported results at most time points after PH (Columbano et al., 2005). Interferon-alpha 1 (IFNA1) can induce apoptosis of hair cells by inhibitors of apoptosis (IAP) (Baker et al., 2002). IFNA1 was downregulated 1, 4, and $12 \mathrm{~h}$ after $\mathrm{PH}$, which indicates that it also inhibits cell apoptosis in liver tissue regeneration. Neutrophil cytosolic factor 1 (NCF1) has been shown to promote angiogenesis (Touyz et al., 2005). NCF1 was upregulated at multiple time points in the stage of cell proliferation, tissue structural and function reconstruction in liver regeneration, and might be related to the growth of the regenerated liver. Reticulon 3 (RTN3) is located in the ER and is involved in the survival and regeneration of nerve cells (Di 
Scala et al., 2005). RTN3 was upregulated during the entirety of liver regeneration and might be related to nerve reconstruction in regenerating liver.

To analyze the correlation between the apoptosis signaling pathway-related genes during rat liver regeneration, the spectrum function $\mathrm{E}(\mathrm{t})$ was used to analyze the gene synergetic effects. The E(t) values indicated that FAS, DR3, TNFR1, and ER pathways promoted cell apoptosis during the entire liver regeneration process. The anti-apoptosis pathways DR3 and TNFR2 were involved in the early stages of liver regeneration.

In summary, the four death receptor- and ER-mediated apoptosis signaling pathways did indeed promote apoptosis of damaged, defective, diseased, and excess cells throughout the liver regeneration process in the rat model, working together to achieve proper regulation of the quality and quantity of regenerating hepatocytes. In the future, we will further verify these results at the cellular level by applying Northern blot, protein chip, RNA interference, and other methods.

\section{Conflicts of interest}

The authors declare no conflict of interest.

\section{ACKNOWLEDGMENTS}

Research supported by grants from the Key Research Project of Henan Province (\#15A180020) and the National Natural Science Foundation of China (\#81502105).

\section{REFERENCES}

Antoku K, Maser RS, Scully WJ, Jr., Delach SM, et al. (2001). Isolation of Bcl-2 binding proteins that exhibit homology with BAG-1 and suppressor of death domains protein. Biochem. Biophys. Res. Commun. 286: 1003-1010. http:// dx.doi.org/10.1006/bbrc.2001.5512

Baker PK, Pettitt AR, Slupsky JR, Chen HJ, et al. (2002). Response of hairy cells to IFN-alpha involves induction of apoptosis through autocrine TNF-alpha and protection by adhesion. Blood 100: 647-653. http://dx.doi.org/10.1182/ blood.V100.2.647

Bender LM, Morgan MJ, Thomas LR, Liu ZG, et al. (2005). The adaptor protein TRADD activates distinct mechanisms of apoptosis from the nucleus and the cytoplasm. Cell Death Differ. 12: 473-481. http://dx.doi.org/10.1038/ sj.cdd. 4401578

Borghetti G, Yamaguchi AA, Aikawa J, Yamazaki RK, et al. (2015). Fish oil administration mediates apoptosis of Walker 256 tumor cells by modulation of p53, Bcl-2, caspase-7 and caspase-3 protein expression. Lipids Health Dis. 14: 94. http://dx.doi.org/10.1186/s12944-015-0098-y

Calvano SE, Xiao W, Richards DR, Felciano RM, et al.; Inflamm and Host Response to Injury Large Scale Collab. Res. Program (2005). A network-based analysis of systemic inflammation in humans. Nature 437: 1032-1037. http:// dx.doi.org/10.1038/nature 03985

Columbano A, Ledda-Columbano GM, Pibiri M, Cossu C, et al. (2005). Gadd45beta is induced through a CAR-dependent, TNF-independent pathway in murine liver hyperplasia. Hepatology 42: 1118-1126. http://dx.doi.org/10.1002/ hep. 20883

Deming PB, Schafer ZT, Tashker JS, Potts MB, et al. (2004). Bcr-Abl-mediated protection from apoptosis downstream of mitochondrial cytochrome c release. Mol. Cell. Biol. 24: 10289-10299. http://dx.doi.org/10.1128/MCB.24.23.1028910299.2004

Di Scala F, Dupuis L, Gaiddon C, De Tapia M, et al. (2005). Tissue specificity and regulation of the N-terminal diversity of reticulon 3. Biochem. J. 385: 125-134. http://dx.doi.org/10.1042/BJ20040458

Díaz-Horta O, Van Eylen F and Herchuelz A (2003). Na/Ca exchanger overexpression induces endoplasmic reticulum stress, caspase-12 release, and apoptosis. Ann. N. Y. Acad. Sci. 1010: 430-432. http://dx.doi.org/10.1196/annals.1299.077 
Drosopoulos KG, Roberts ML, Cermak L, Sasazuki T, et al. (2005). Transformation by oncogenic RAS sensitizes human colon cells to TRAIL-induced apoptosis by up-regulating death receptor 4 and death receptor 5 through a MEKdependent pathway. J. Biol. Chem. 280: 22856-22867. http://dx.doi.org/10.1074/jbc.M412483200

Durmuş S, Çakır T, Özgür A and Guthke R (2015). A review on computational systems biology of pathogen-host interactions. Front. Microbiol. 6: 235.

Fair JM and Rivas AL (2015). Systems biology and ratio-based, real-time disease surveillance. Transbound. Emerg. Dis. 62: 437-445. http://dx.doi.org/10.1111/tbed.12162

Galluzzi L, Bravo-San Pedro JM and Kroemer G (2014). Organelle-specific initiation of cell death. Nat. Cell Biol. 16: 728-736. http://dx.doi.org/10.1038/ncb3005

Green DR and Kroemer G (2004). The pathophysiology of mitochondrial cell death. Science 305: 626-629. http://dx.doi. org/10.1126/science.1099320

Hosono-Nishiyama K, Matsumoto T, Kiyohara H, Nishizawa A, et al. (2006). Suppression of Fas-mediated apoptosis of keratinocyte cells by chikusetsusaponins isolated from the roots of Panax japonicus. Planta Med. 72: 193-198. http:// dx.doi.org/10.1055/s-2005-916176

Jun JI, Chung CW, Lee HJ, Pyo JO, et al. (2005). Role of FLASH in caspase-8-mediated activation of NF-kappaB: dominant-negative function of FLASH mutant in NF-kappaB signaling pathway. Oncogene 24: 688-696. http:// dx.doi.org/10.1038/sj.onc. 1208186

Korn C, Scholz SR, Gimadutdinow O, Lurz R, et al. (2005). Interaction of DNA fragmentation factor (DFF) with DNA reveals an unprecedented mechanism for nuclease inhibition and suggests that DFF can be activated in a DNA-bound state. J. Biol. Chem. 280: 6005-6015. http://dx.doi.org/10.1074/jbc.M413035200

Kurenova E, Xu LH, Yang X, Baldwin AS, Jr., et al. (2004). Focal adhesion kinase suppresses apoptosis by binding to the death domain of receptor-interacting protein. Mol. Cell. Biol. 24: 4361-4371. http://dx.doi.org/10.1128/ MCB.24.10.4361-4371.2004

Kwon KB, Park EK, Ryu DG and Park BH (2002). D4-GDI is cleaved by caspase-3 during daunorubicin-induced apoptosis in HL-60 cells. Exp. Mol. Med. 34: 32-37. http://dx.doi.org/10.1038/emm.2002.5

Liu H and Baliga R (2005). Endoplasmic reticulum stress-associated caspase 12 mediates cisplatin-induced LLC-PK1 cell apoptosis. J. Am. Soc. Nephrol. 16: 1985-1992. http://dx.doi.org/10.1681/ASN.2004090768

MacLachlan TK and El-Deiry WS (2002). Apoptotic threshold is lowered by p53 transactivation of caspase-6. Proc. Natl. Acad. Sci. USA 99: 9492-9497. http://dx.doi.org/10.1073/pnas.132241599

Meaburn KJ, Levy N, Toniolo D and Bridger JM (2005). Chromosome positioning is largely unaffected in lymphoblastoid cell lines containing emerin or A-type lamin mutations. Biochem. Soc. Trans. 33: 1438-1440. http://dx.doi. org/10.1042/BST0331438

Neznanov N, Neznanova L, Angres B and Gudkov AV (2005). Serologically defined colon cancer antigen 3 is necessary for the presentation of TNF receptor 1 on cell surface. DNA Cell Biol. 24: 777-785. http://dx.doi.org/10.1089/ dna.2005.24.777

Nishito Y, Hasegawa M, Inohara N and Núñez G (2006). MEX is a testis-specific E3 ubiquitin ligase that promotes death receptor-induced apoptosis. Biochem. J. 396: 411-417. http://dx.doi.org/10.1042/BJ20051814

Puthalakath H, Villunger A, O'Reilly LA, Beaumont JG, et al. (2001). Bmf: a proapoptotic BH3-only protein regulated by interaction with the myosin V actin motor complex, activated by anoikis. Science 293: 1829-1832. http://dx.doi. org/10.1126/science. 1062257

Qing G and Xiao G (2005). Essential role of IkappaB kinase alpha in the constitutive processing of NF-kappaB2 p100. J. Biol. Chem. 280: 9765-9768. http://dx.doi.org/10.1074/jbc.C400502200

Tomasetti M, Andera L, Alleva R, Borghi B, et al. (2006). Alpha-tocopheryl succinate induces DR4 and DR5 expression by a p53-dependent route: implication for sensitisation of resistant cancer cells to TRAIL apoptosis. FEBS Lett. 580: 1925-1931. http://dx.doi.org/10.1016/j.febslet.2006.02.054

Touyz RM, Yao G, Quinn MT, Pagano PJ, et al. (2005). p47phox associates with the cytoskeleton through cortactin in human vascular smooth muscle cells: role in $\mathrm{NAD}(\mathrm{P}) \mathrm{H}$ oxidase regulation by angiotensin II. Arterioscler. Thromb. Vasc. Biol. 25: 512-518. http://dx.doi.org/10.1161/01.ATV.0000154141.66879.98

Tran NL, McDonough WS, Savitch BA, Sawyer TF, et al. (2005). The tumor necrosis factor-like weak inducer of apoptosis (TWEAK)-fibroblast growth factor-inducible 14 (Fn14) signaling system regulates glioma cell survival via NFkappaB pathway activation and BCL-XL/BCL-W expression. J. Biol. Chem. 280: 3483-3492. http://dx.doi. org/10.1074/jbc.M409906200

Ventura E, Balza E, Borsi L, Tutolo G, et al. (2011). Selective targeted delivery of the TNF-alpha receptor p75 and uteroglobin to the vasculature of inflamed tissues: a preliminary report. BMC Biotechnol. 11: 104. http://dx.doi. org/10.1186/1472-6750-11-104 
Xu C, Yang Y, Yang J, Chen X, et al. (2012). Analysis of the role of the integrin signaling pathway in hepatocytes during rat liver regeneration. Cell. Mol. Biol. Lett. 17: 274-288. http://dx.doi.org/10.2478/s11658-012-0011-x

Xu CS, Chang CF, Yuan JY, Li WQ, et al. (2005). Expressed genes in regenerating rat liver after partial hepatectomy. World J. Gastroenterol. 11: 2932-2940. http://dx.doi.org/10.3748/wjg.v11.i19.2932

Zhang R, Luo D, Miao R, Bai L, et al. (2005). Hsp90-Akt phosphorylates ASK1 and inhibits ASK1-mediated apoptosis. Oncogene 24: 3954-3963. http://dx.doi.org/10.1038/sj.onc.1208548 